\title{
MJFA MMALSAMNOONNA OF

\section{Antioxidants and cactus extract enhances the sun protection factor of octocrylene and oxybenzone solution}

\author{
Jingyi Lim, Jie Yong Chan, Lai Chun Wong * \\ Department of Pharmaceutical Chemistry, School of Pharmacy, International Medical University, 57000 Kuala Lumpur, Malaysia \\ * Corresponding author: laichunwong@imu.edu.my
}

\section{Article history}

Received 23 June 2018

Revised 2 August 2018

Accepted 11 October 2018

Published Online 25 August 2019

\begin{abstract}
Ultraviolet (UV) filters such as octocrylene and oxybenzone in topical photoprotection products work effectively in absorbing UV radiation, thus minimizing sun damage to the skin. Antioxidants are incorporated into sunscreen products to enhance the photoprotection ability of the products. However, the effectiveness of the antioxidants on the sun protection factor (SPF) of UV filters is not well established. Hence in this study, the effect of caffeine, nicotinamide, $\beta$-carotene, $\alpha$-tocopherol, and cactus extract on the SPF of octocrylene and oxybenzone were investigated. The UV absorbance of octocrylene $(5 \mu \mathrm{g} / \mathrm{mL})$ and oxybenzone $(20 \mu \mathrm{g} / \mathrm{mL})$ in $95 \%$ ethanol, with different concentrations of the antioxidants $(0.1-100 \mu \mathrm{g} / \mathrm{mL})$ and cactus extract were measured from 290 $320 \mathrm{~nm}$. The UV absorbance values were converted to SPF values by the Mansur equation. Statistical analysis was performed by ANOVA test and Post Hoc test (Dundett T3 test) with a significance level of $p<0.05$ using SPSS software. The antioxidants and cactus extract were found to significantly increase the SPF of octocrylene and oxybenzone solutions in a concentrationdependent manner. Out of the antioxidants tested, $\beta$-carotene and $\alpha$-tocopherol were the most effective antioxidants to increase the SPF of octocrylene solution and oxybenzone solutions, respectively. The results supported that it is beneficial to incorporate antioxidants and cactus extract into the formulation of topical photoprotection products.
\end{abstract}

Keywords: Octocrylene, oxybenzone, sun protection factor (SPF), antioxidants, cactus extract

\section{INTRODUCTION}

Ultraviolet (UV) radiation can be classified as UVA (315-400 nm), UVB (290-320 nm), or UVC (100-280 nm) (Latha et al., 2013), with UVB being a key role in the development of skin cancer and many other environmentally-influenced skin disorders (D'Orazio, Jarrett, Amaro-Ortiz, \& Scott, 2013). Therefore, it is important to apply topical photoprotection agents before sun exposure. Organic chemical and physical mineral type sunscreen agents effectively minimize sun damage to the skin via different mechanisms. Physical mineral type sunscreen agents such as zinc oxide and titanium dioxide reflect, scatter, or block the UV radiation. Meanwhile, organic chemical sunscreen agents absorb the harmful UV rays and dissipating it as heat (Latha et al., 2013).

The efficiency of a sunscreen is usually expressed by the sun protection factor (SPF). The SPF is defined as the UV energy required to produce a minimal erythema dose (MED) on protected skin, divided by the UV energy required to produce a MED on unprotected skin (Dutra, Oliveira, Kedor-Hackmann, \& Santoro, 2004). Hence, sunscreens with higher SPF values provide longer exposure before the skin experiences sunburn. In the European Union and ASEAN countries, SPF classification of sunscreen products is labeled from low protection (SPF 6) to very high protection (SPF 50+) (Pirotta, 2015). SPF 15 is the FDA's minimum recommendation for protection against skin cancer and sunburn. Generally, in vitro methods to measure SPF involves the measurement of absorption or the transmission of UV radiation through sunscreen product films in quartz plates or biomembranes. The other common method involves the determination of the absorption characteristics of the sunscreen agents based on spectrophotometric analysis of dilute solutions (Mansur, Breder, Mansur, \& Azulay, 1986).

Antioxidants are increasingly being incorporated into sunscreen formulations due to their ability to provide supplemental photoprotection by scavenging free radicals formed as a result of sun radiation (Wu et al., 2011). However, the effect of antioxidants on the SPF of sunscreen agents are not well studied. Therefore, we were interested to assess whether the addition of antioxidants would increase the photoprotective capability of the sunscreen agents octocrylene, a UVA and UVB filter and oxybenzone, a UVB filter. In addition to the antioxidants, the effect of cactus extract on the SPF of the sunscreen agents was assessed as well as various part of cactus plant have been reported to contain antioxidant activity (Ammar, Ennouri, \& Attia, 2015; Fernández-López, Almela, Obón, \& Castellar, 2010). Octocrylene and oxybenzone have been approved by the Federal Drug and Administration (FDA) for use in sunscreen formulations at concentrations up to $10 \%$ and $6 \%$, respectively (Pirotta, 2015). In this project, the effect of the antioxidants ascorbic acid, nicotinamide, caffeine, $\beta$-carotene, $\alpha$-tocopherol, and cactus extract on the SPF of octocrylene and oxybenzone were studied.

\section{EXPERIMENTAL}

\section{Chemicals and reagents}

Nicotinamide, $\alpha$-tocopherol, caffeine, L-ascorbic acid, and $\beta$ carotene were obtained from Sigma-Aldrich (USA). Oxybenzone and octocrylene were obtained from Merck (Darmstadt, Germany). 


\section{Preparation of antioxidant stock solutions}

Individual stock solutions of nicotinamide, $\alpha$-tocopherol, caffeine, and $\beta$-carotene of concentration $1000 \mu \mathrm{g} / \mathrm{mL}$ were prepared in $95 \%$ ethanol. The stock solutions were filtered using a $0.22 \mu \mathrm{m}$ nylon membrane filter.

\section{Determination of the SPF values}

The SPF value of the solutions were calculated by using the Mansur equation:

$$
\text { SPF spectrophotometric }=\mathrm{CF} \times \sum_{290}^{320} \mathrm{EE}(\lambda) \times \mathrm{I}(\lambda) \times \operatorname{Abs}(\lambda)
$$

where $\mathrm{EE}=$ erythemal effeciency spectrum; $\mathrm{I}=$ solar simulator intensity spectrum; $\mathrm{Abs}=$ absorbance of sunscreen product; $\mathrm{CF}=$ correction factor $(=10)$. The values of EE $x$ I are constants as determined by Sayre, Agin, Le Vee, and Marlowe (1979).

Table 1 The normalized product function used in the calculation of SPF data.

\begin{tabular}{lc}
\hline Wavelength $(\boldsymbol{\lambda} \mathbf{~ n m})$ & $\begin{array}{c}\text { EE X I } \\
\text { (normalized) }\end{array}$ \\
\hline $\mathbf{2 9 0}$ & 0.0150 \\
$\mathbf{2 9 5}$ & 0.0817 \\
$\mathbf{3 0 0}$ & 0.2874 \\
$\mathbf{3 0 5}$ & 0.3278 \\
$\mathbf{3 1 0}$ & 0.1864 \\
$\mathbf{3 1 5}$ & 0.0839 \\
$\mathbf{3 2 0}$ & 0.0180 \\
Total & 1.0000 \\
\hline
\end{tabular}

\section{Determination of the SPF of antioxidant solutions}

The stock solutions of each of the antioxidants were diluted accordingly with $95 \%$ ethanol to obtain working solution of concentrations $0.1 \mu \mathrm{g} / \mathrm{mL}, 1 \mu \mathrm{g} / \mathrm{mL}, 10 \mu \mathrm{g} / \mathrm{mL}, 20 \mu \mathrm{g} / \mathrm{mL}, 40 \mu \mathrm{g} / \mathrm{mL}$, $50 \mu \mathrm{g} / \mathrm{mL}, 60 \mu \mathrm{g} / \mathrm{mL}, 80 \mu \mathrm{g} / \mathrm{mL}$, and $100 \mu \mathrm{g} / \mathrm{mL}$. The absorbance of the solutions were measured immediately between $290-320 \mathrm{~nm}$, at every interval of $5 \mathrm{~nm}$. Three replicate measurements were made for every solution. The measured absorbance values were then applied into the Mansur equation to obtain the SPF values.

\section{Determination of the SPF of octocrylene with antioxidants}

Octocrylene solution of concentration $5 \mu \mathrm{g} / \mathrm{mL}$ was prepared in $95 \%$ ethanol. The antioxidant stock solutions were diluted accordingly with the $5 \mu \mathrm{g} / \mathrm{mL}$ octocrylene solution to obtain working antioxidant stock solution with concentrations of $0.1 \mu \mathrm{g} / \mathrm{mL}, 1 \mu \mathrm{g} / \mathrm{mL}, 10 \mu \mathrm{g} / \mathrm{mL}$, $20 \mu \mathrm{g} / \mathrm{mL}, 40 \mu \mathrm{g} / \mathrm{mL}, 50 \mu \mathrm{g} / \mathrm{mL}, 60 \mu \mathrm{g} / \mathrm{mL}, 80 \mu \mathrm{g} / \mathrm{mL}$, and $100 \mu \mathrm{g} / \mathrm{mL}$. The absorbance of the solutions were measured immediately between 290-320 nm, at every interval of $5 \mathrm{~nm}$. Three replicate measurements were made for every solution. The measured absorbance values were then applied into the Mansur equation to obtain the SPF values.

\section{Determination of the SPF of oxybenzone with antioxidants}

Oxybenzone solution of concentration $20 \mu \mathrm{g} / \mathrm{mL}$ was prepared in $95 \%$ ethanol. The antioxidant stock solutions were diluted accordingly with the oxybenzone solution to obtain working antioxidant stock solutions with concentration $0.1 \mu \mathrm{g} / \mathrm{mL}, 1 \mu \mathrm{g} / \mathrm{mL}, 10 \mu \mathrm{g} / \mathrm{mL}, 20 \mu \mathrm{g} / \mathrm{mL}$, $40 \mu \mathrm{g} / \mathrm{mL}, 50 \mu \mathrm{g} / \mathrm{mL}, 60 \mu \mathrm{g} / \mathrm{mL}, 80 \mu \mathrm{g} / \mathrm{mL}$, and $100 \mu \mathrm{g} / \mathrm{mL}$. The absorbance of the solutions was measured immediately between 290 $320 \mathrm{~nm}$, at every interval of $5 \mathrm{~nm}$. Three replicate measurements were made for every solution. The measured absorbance values were then applied into the Mansur equation to obtain the SPF values.

\section{Determination of the SPF of cactus extract $(3.78 \mathrm{mg} / \mathrm{mL}$ and $75.52 \mathrm{mg} / \mathrm{mL}$ )}

The cactus plant (Echinocactus Grusonii) was purchased from a supermarket in Kuala Lumpur. The thorns were removed from the plant, and the bark was cut into pieces. The cactus pieces were left to air dry for a week. The dried cactus pieces $(3.78 \mathrm{~g})$ were refluxed with methanol for three hours to extract out the photoactive components. The cactus pieces were discarded, and the solvent was removed using a rotary evaporator. The dried extract was reconstituted with $10 \mathrm{~mL}$ of
$95 \%$ ethanol to produce a stock cactus extract solution of $0.38 \mathrm{~g} / \mathrm{mL}$. As the absorbance of the stock cactus solution exceeded the spectrophotometer measurement limit, the stock cactus solution was further diluted accordingly with 95\% ethanol solution to working concentrations of $75.52 \mathrm{mg} / \mathrm{mL}$ and $3.78 \mathrm{mg} / \mathrm{mL}$. The concentration of the working solutions were within the the lower and higher measurement range of the spectrophotometer. The absorbance of the working solutions was measured immediately between $290-320 \mathrm{~nm}$, at every interval of $5 \mathrm{~nm}$. Three replicate measurements were made for every solution. The measured absorbance values were then applied into the Mansur equation to obtain the SPF values.

\section{Effect of cactus extract on the SPF of sunscreen solutions}

Solutions of cactus extract $(3.78 \mathrm{mg} / \mathrm{mL})$ in combination with each sunscreen agent were prepared in $95 \%$ ethanol. The concentrations of oxybenzone and octocrylene were $20 \mu \mathrm{g} / \mathrm{mL}$ and $5 \mu \mathrm{g} / \mathrm{mL}$, respectively. The absorbance of the mixed solutions was measured immediately between $290-320 \mathrm{~nm}$, at every interval of $5 \mathrm{~nm}$. Three replicate measurements were made for every solution. The measured absorbance values were then applied into the Mansur equation to obtain the SPF values.

\section{High performance liquid chromatography (HPLC) analysis of cactus extract}

Chromatography was performed on a 1200 series HPLC (Agilent Technologies, US), interfaced with a binary pump (G1312A, Agilent Technologies, US), degasser (G1379B, Agilent Technologies, US), variable wavelength detector (VWD) (Agilent Technologies, US), and manual injector (G1328B, Agilent Technologies, US). The HPLC was interfaced to a Hewlett-Packard L1908 computer equipped with ChemStation System (version 2008) software. Separation was achieved in a C18 Hypersil GOLD column (150 mm x $4.6 \mathrm{~mm}$ internal diameter, $5 \mu \mathrm{m}$ particle size) at room temperature. The mobile phase was composed of (A) water and (B) methanol, with a flow rate of $1 \mathrm{~mL} / \mathrm{min}$ set at gradient elution starting from 10:90 (methanol:water), and increasing to $100 \%$ methanol within 10 minutes. The mobile phase was held at $100 \%$ methanol for 9 minutes. The injection loop volume was $20 \mu \mathrm{l}$ and the detection wavelength was set at $254 \mathrm{~nm}$.

\section{Statistical analysis}

Data are presented as the mean \pm standard deviation. The significance difference $(\mathrm{P}>0.05)$ between SPF values were determined by ANOVA and Post-Hoc test (Tukey and Dunnett's) using SPSS software.

\section{RESULTS AND DISCUSSION}

\section{SPF of antioxidant solutions}

To assess whether the antioxidants in this study (Fig. 1) exhibited photoprotective properties, the SPF of the antioxidants in $95 \%$ ethanol was measured. In general, the SPF of the antioxidant solutions were found to be proportional to concentration (Fig. 2). The $\beta$-carotene solution had the highest coefficient of determination $\left(\mathrm{R}^{2}\right)$ value which was 0.9988 , followed by caffeine (0.9980), $\alpha$-tocopherol (0.9909), and lastly, nicotinamide $(0.9327)$. In general, $\beta$-carotene solution was found to have the highest SPF potency followed by $\alpha$-tocopherol, caffeine, and lastly nicotinamide. With larger conjugation systems, the absorption spectra of organic compounds tend to be shifted toward the long wavelength region. $\beta$-carotene, being highly conjugated experiences bathochromic shift where the absorption peak wavelength is shifted towards the UVB region of the spectrum, hence the high SPF obtained from $\beta$-carotene solution in this experiment. The results suggested that $\beta$-carotene can be used as a natural sunscreen agent. Topical administration of $\beta$-carotene induces statistically significant increase of the antioxidant levels in human skin (Darvin, Fluhr, Schanzer, et al., 2011). While $\beta$-carotene have been shown to provide photoprotection by nutritional means, topical application has the benefit of instant photoprotection effect and higher SPF. With dietary carotenoids on the other hand, there is in general a time frame of 7 to 10 weeks until protection against erythema formation becomes 
significant (Stahl \& Sies, 2012). An additional benefit of topical application over dietary $\beta$-carotene is that $\beta$-carotene supplements have been shown to increase the incidence of lung cancer in individuals with high risk of cancer (Stahl \& Sies, 2012). However, in general it is recommended that both dietary and topical photoprotection are complementary to each other.
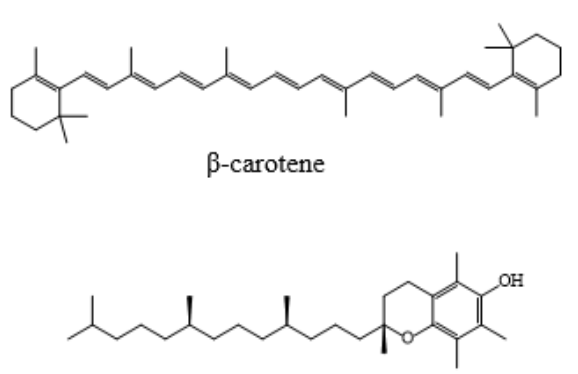

$\alpha$-tocopherol

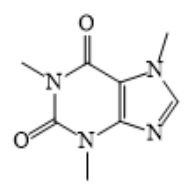

caffeine

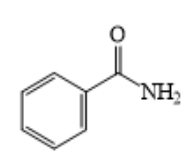

nicotinamide
Fig. 1 The antioxidants studied in this work.

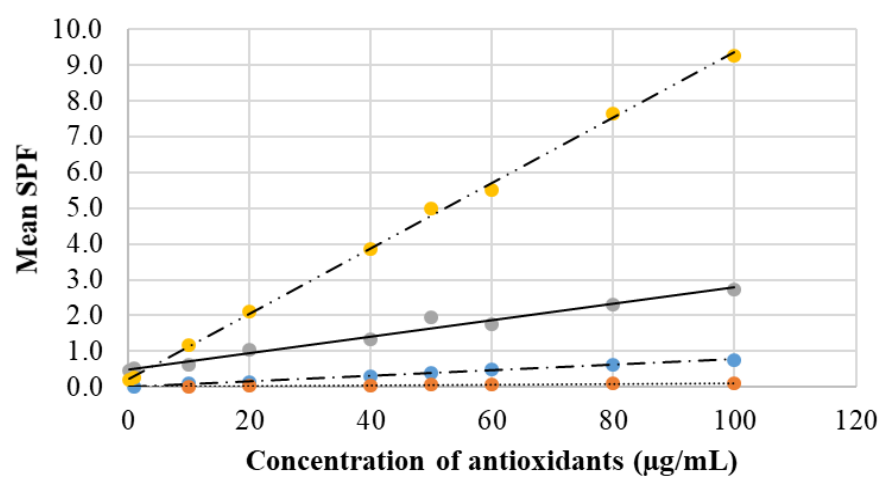

$$
\begin{array}{ll}
-\cdot-\text { Linear (caffeine) } & \cdots \cdots \cdots \cdots \cdots \cdot \text { Linear (nicotinamide) } \\
\text { - Linear }(\alpha \text {-tocopherol) } & -\cdots-\text { Linear }(\beta \text {-carotene })
\end{array}
$$

Fig. 2 The mean SPF $(n=3)$ values of antioxidant solutions from concentration $0.1-100 \mu \mathrm{g} / \mathrm{mL}$ in $95 \%$ ethanol.

It is worth to note that the SPF of L-ascorbic acid solution was also investigated (Fig. 3). However, the $\mathrm{R}^{2}$ value of the concentration curve of L-ascorbic acid was found to be 0.2593 , indicating that there is no linear relationship between SPF and concentration. The inconsistency in the SPF observed for L-ascorbic solutions may be caused by the degradation of L-ascorbic acid in ethanol solution. Ascorbic acid has been shown to degrade in ethanolic solutions during storage, and that the degradation rates increase with the increase of ethanol concentration (Yuan \& Chuan, 1998). Therefore, we suggest that in topical formulations containing L-ascorbic acid, high concentrations of ethanol should be avoided. As ascorbic acid is highly sensitive to air and light, various solutions have been proposed to achieve stabilization of ascorbic acid in cosmetic and pharmaceutical applications (M. Sheraz et al., 2011; M. A. Sheraz, Khan, Ahmed, Kazi, \& Ahmad, 2015). Among the reported method is to use ascorbic acid in combination with other vitamins, such as $\alpha$-tocopherol, to retard its oxidative degradation. The stability of ascorbic acid in oil-water creams were found to be highest in the presence of $\alpha$-tocopherol compared to other vitamins including riboflavin and nicotinamide (Sheraz et al., 2015). Therefore, we were interested to investigate the SPF property of mixtures containing both L-ascorbic acid and $\alpha$-tocopherol. L-ascorbic acid $(20 \mu \mathrm{g} / \mathrm{mL})$ solution in varying concentrations of $\alpha$-tocopherol $(0.1-100 \mu \mathrm{g} / \mathrm{mL})$ was prepared in $95 \%$ ethanol, and the SPF were calculated from the absorbance values (Fig. 4).

We found that the SPF of the mixture solution increased proportionally to the concentration of $\alpha$-tocopherol, with $\mathrm{R}^{2}$ value of 0.994. However, the SPF of the mixture solutions were found to be lower compared to the solution of $\alpha$-tocopherol alone. This suggest that the addition of L-ascorbic acid may have decreased the UV absorbing properties of $\alpha$-tocopherol. Interestingly, Khamsiah et al. (2012) reported that photoprotection was best achieved when sunscreens are used together with creams containing either vitamin $\mathrm{C}$ or $\mathrm{E}$ alone. The authors found that combining vitamins $\mathrm{C}$ and $\mathrm{E}$ rich creams with sunscreens had no effect on the SPF compared to the use of a single vitamin (Khamsiah et al., 2012). Nevertheless, in vivo studies have suggested the benefits of combining topical vitamins $\mathrm{C}$ and $\mathrm{E}$ to protect the skin against $\mathrm{UV}$ irradiation and photoprotection (Ba, Hu, \& Wang, 2012; Lin et al., 2003). However, it has been suggested that protection by the combination of these two antioxidants is not by their sunscreen effect, but mainly as a consequence of the potent antioxidant properties of both of the vitamins (Dreher, Gabard, Schwindt, \& Maibach, 1998). Ebrahimzadeh et al. (2014) found no correlation between antioxidant activity and SPF of some medicinal plants. Hence, in a mixture of various antioxidants, the antioxidant property may not correlate with $\mathrm{SPF}$ values. Therefore, although we have shown that $\mathrm{L}$-ascorbic acid may reduce the SPF property of $\alpha$-tocopherol, the photoprotection in terms of increased antioxidant activity obtained with the combination mixture may outweigh the reduction in SPF. To compensate for the reduction in SPF, we suggest that formulations containing both of the antioxidants should contain additional photoprotective agents with potent UVB absorbing properties.

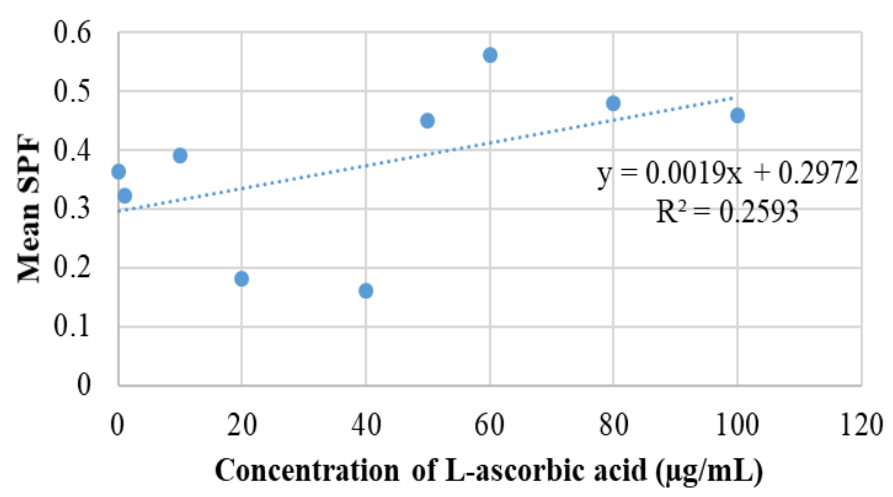

Fig. 3 The mean SPF $(n=3)$ values of $L$-ascorbic acid from concentration $0.1-100 \mu \mathrm{g} / \mathrm{mL}$ in $95 \%$ ethanol.

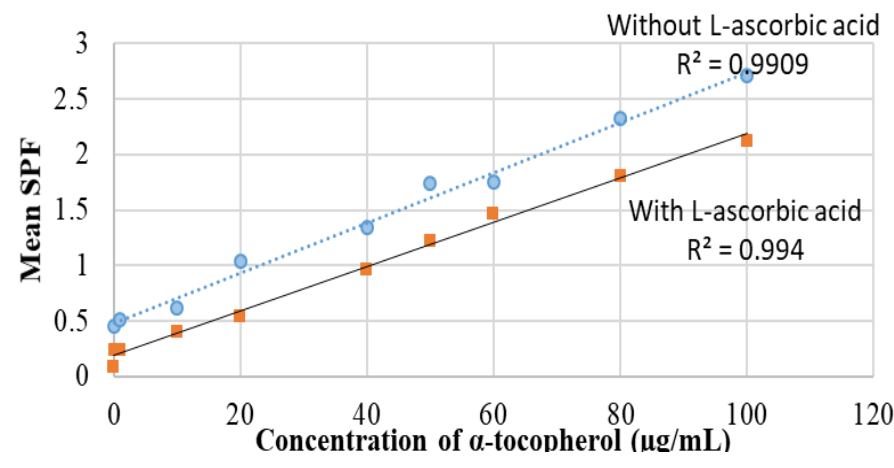

Fig. 4 Normalized mean SPF $(n=3)$ values of $\alpha$-tocopherol solution $(0.1-$ $100 \mu \mathrm{g} / \mathrm{mL})$, with and without the addition of L-ascorbic acid $(20 \mu \mathrm{g} / \mathrm{mL})$.

\section{Effect of antioxidants on the SPF of sunscreen agents}

To study the effect of antioxidants on the SPF of the sunscreen agents, solution of sunscreen agents in $95 \%$ ethanol with various concentration of antioxidant $(0.1-100 \mu \mathrm{g} / \mathrm{mL})$ were prepared. The absorbance of these solutions at $290-310 \mathrm{~nm}$ were measured with UV/VIS spectrophotometer. The SPF of the solutions were then determined using the Mansur equation. In general, addition of the antioxidants was found to significantly increase the protective capability of the sunscreen agents.

$\beta$-carotene was found to have the largest effect on the SPF of octocrylene solution, while $\alpha$-tocopherol had the largest effect on the 
SPF of oxybenzone solution (Figs. 5 and 6). This results supports that incorporating antioxidants with sunscreen agents can contribute to SPF value. In human models, topical application of sunscreen formulations with mixture of antioxidants including caffeine, tocopherol acetate and vitamin $\mathrm{E}$ have been shown to further decrease UV-induced damage compared with sunscreen alone (Matsui et al., 2009; Wu et al., 2011) Interestingly, $\mathrm{Wu}$ et al. (2011) reported that protection against induction of MMP-9, a marker of photoaging, was not significant when either sunscreen formulation or antioxidant formulation were applied separately. However, complete protection against MMP-9 induction was observed when the two were combined. The mechanism of the added photoprotection by the antioxidants have been attributed to their ability to boost the body's natural reserve and neutralize reactive oxygen species (ROS) from intrinsic sources (e.g. cellular metabolism) and extrinsic factors (e.g. UV damage). UVA is particularly efficient at inducing ROS and is considered to be a major contributor to the process of cutaneous photodamage and photoaging (Wang, Osterwalder, \& Jung, 2011). However, our results suggested that in addition to quenching ROS, the antioxidants tested in this study were also capable of enhancing the photoprotection of sunscreen agents by absorption of the UV radiation, indicated by the increase in the SPF. The antioxidants studied in this project are natural compounds and are relatively safe to be included into topical skincare products. Vitamins $\mathrm{C}, \mathrm{E}$, and $\beta$ carotene are well-characterized vitamins which are commonly added into commercial sunscreen preparations (Pinnell, 2003), with tocopherol being the most predominant vitamin found in sunscreens (Monico et al., 2015). The normal content of the antioxidants studied in this project in commercially available topical formulations as well as their reported benefit as topical application is listed in Table 2 .

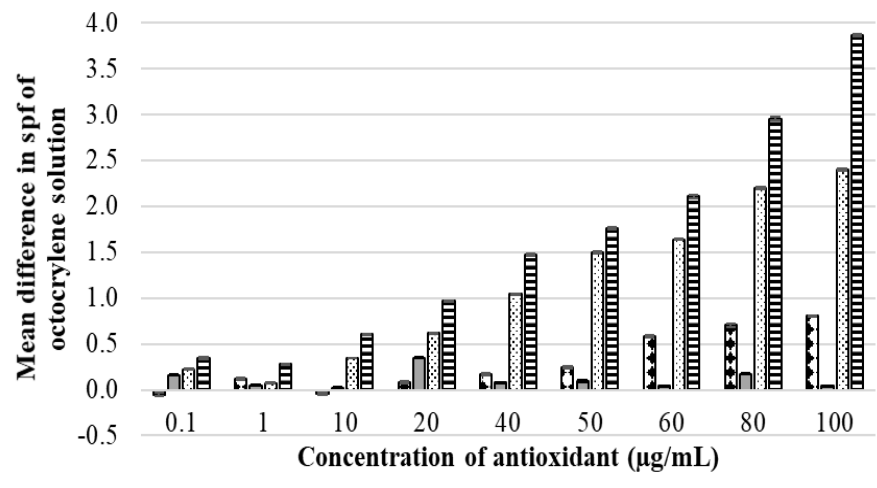

ФCaffeine $\square$ Nicotinamide $\quad \nabla \alpha$-tocopherol $\quad$ $\beta$-carotene

Fig. 5 Difference in mean SPF $(n=3)$ of octocrylene solution $(5 \mu \mathrm{g} / \mathrm{mL})$ with antioxidants compared to without antioxidants. The values are obtained by subtracting the mean SPF value of solutions containing antioxidants with the mean SPF without any antioxidants.

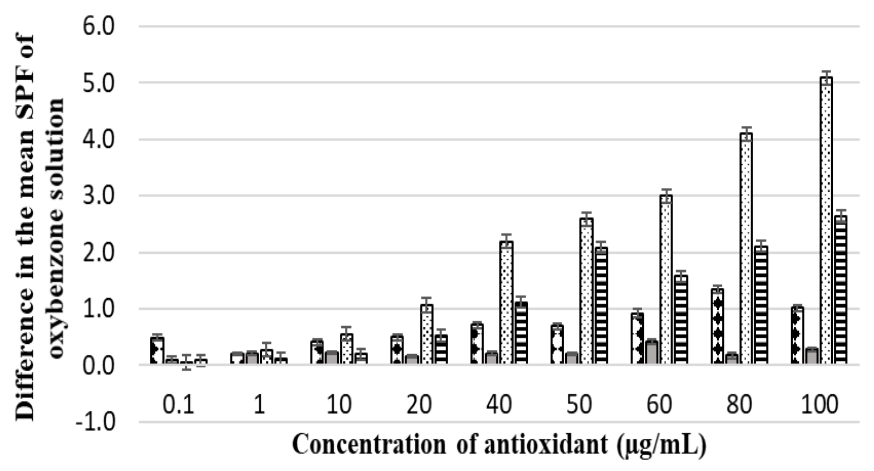

Bcaffeine $\square$ nicotinamide $\quad \alpha \alpha$-tocopherol $\quad \boxminus \beta$-carotene

Fig. 6 Difference in mean SPF $(\mathrm{n}=3)$ of oxybenzone solution $(20 \mu \mathrm{g} / \mathrm{mL})$ with antioxidants compared to without antioxidants. The values are obtained by subtracting the mean SPF value of solutions containing antioxidants with the mean SPF without any antioxidants.
Table 2 The typical content of the antioxidants used in this study in topical formulations.

\begin{tabular}{|c|c|c|}
\hline Antioxidants & $\begin{array}{l}\text { Typical } \\
\text { content }\end{array}$ & $\begin{array}{l}\text { Beneficial properties as topical } \\
\text { application }\end{array}$ \\
\hline caffeine & $\begin{array}{l}\text { Up to 3\% } \\
\text { (Herman \& } \\
\text { Herman, } \\
\text { 2012) }\end{array}$ & $\begin{array}{l}\text { Photo aging, anticellulite, } \\
\text { antioxidant, hair growth promoter, } \\
\text { increases the microcirculation of } \\
\text { blood in the skin (Herman \& } \\
\text { Herman, 2012). }\end{array}$ \\
\hline nicotinamide & $\begin{array}{l}\text { Up to } 4 \% \\
\text { (Damian, } \\
2010 \text { ) }\end{array}$ & $\begin{array}{l}\text { Anti-inflammatory, antipruritic, } \\
\text { lightening, antimicrobial, } \\
\text { photoprotective (Wohlrab \& Kreft, } \\
\text { 2014). }\end{array}$ \\
\hline vitamin $\mathrm{E}$ & $\begin{array}{l}0.5 \text { to } 1 \% \\
\text { (Keen \& } \\
\text { Hassan, } \\
2016)\end{array}$ & $\begin{array}{l}\text { Antioxidant, skin aging, treatment } \\
\text { of granuloma annulare, reducing } \\
\text { dark under-eye circles (Keen \& } \\
\text { Hassan, 2016). }\end{array}$ \\
\hline$\beta$-carotene & Not available & $\begin{array}{l}\text { UVA/VIS protection (J. V. Freitas } \\
\text { \& Gaspar, 2016), infra-red } \\
\text { protection (Darvin, Fluhr, Meinke, } \\
\text { et al., 2011), improves cutaneous } \\
\text { penetration of UV filters (J. V. } \\
\text { Freitas, Praça, Bentley, \& Gaspar, } \\
\text { 2015), improves photostability of } \\
\text { sunscreen agent (J. V. Freitas, } \\
\text { Lopes, \& Gaspar, 2015). }\end{array}$ \\
\hline
\end{tabular}

The mechanism of the SPF enhancing properties of the antioxidants observed in this work remains to be investigated. If the increased in UV absorbance of the sunscreen solutions with the antioxidants were caused by the additive effect of the SPF of the antioxidants, then we would have expected the SPF of the sunscreen solutions to be affected to the similar extend by the same antioxidants. However, this was not what we observed. For octocrylene solution, increase in SPF was most prominent with $\beta$-carotene, followed by $\alpha$ tocopherol, caffeine, and lastly nicotinamide. In the case of oxybenzone, increase in SPF was most prominent with $\alpha$-tocopherol, followed by $\beta$-carotene, caffeine and lastly nicotinamide.

\section{Determination of the SPF of cactus extract}

The mean SPF of the cactus extract solution of concentration 3.78 $\mathrm{mg} / \mathrm{mL}$ and $75.52 \mathrm{mg} / \mathrm{mL}$ were calculated as $10.72 \pm 0.06$ and $5.32 \pm$ 0.01 , respectively. The observed result suggested that the cactus extract contains compounds capable of absorbing UV radiation between the region $290-310 \mathrm{~nm}$, as also indicated by the absorbance spectrum of the cactus extract (Fig. 7). The SPF of the cactus extract was found to be concentration dependent (Fig. 8).

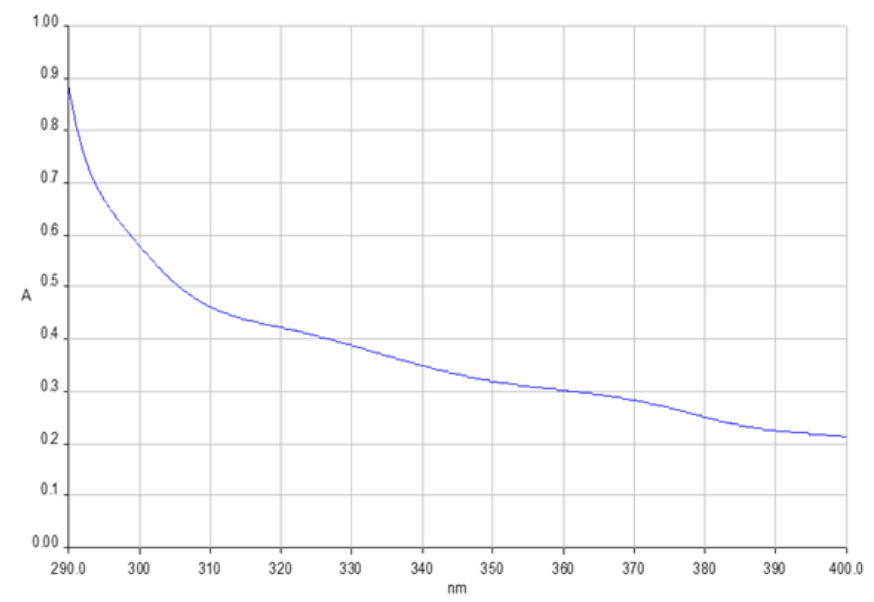

Fig. 7 UV absorbance spectrum of the cactus extract $(3.78 \mathrm{mg} / \mathrm{mL})$. The absorbance spectrum was measured with a Perkin Elmer Lambda 25 UV-VIS Spectrometer. 


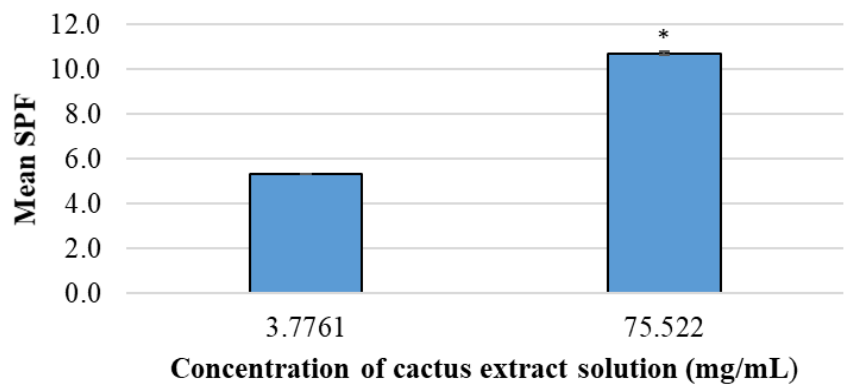

Fig. 8 Mean SPF values of cactus extract solutions $(n=3)$. Significance difference $(p<0.05)$ in SPF of $75.52 \mathrm{mg} / \mathrm{mL}$ cactus solution compared to $3.77 \mathrm{mg} / \mathrm{mL}$ cactus solution is indicated by the asterisk sign.

Naturally derived compounds are attractive sources of photoprotection, as they are considered safer to human health compared to synthetic sunscreens. The cactus extract could be potentially used as natural sunscreen agent to replace or reduce the concentration of synthetic sunscreen agents. The observed SPF property of the cactus extract may be due to the presence of UV absorbing compounds present in plants such as flavonoids. Flavonoid is an ubiquitous group of naturally occurring polyphenolic compounds characterized by the flavan nucleus. The amount of flavonoids produced by a plant is considered an important factor in the protection of the plant against ultraviolet radiation (Saewan \& Jimtaisong, 2013). Infrared analysis was performed on the cactus extract which showed absorption bands at $3364 \mathrm{~cm}^{-1}$ (broad) and $1614 \mathrm{~cm}^{-1}$, which possibly corresponded to $\mathrm{O}-\mathrm{H}$ stretch and $\mathrm{C}=\mathrm{O}$ (conjugated) stretch of the flavonoids (Fig. 9). However, it cannot be determined at this stage if flavonoids are present in the cactus extract, and further work is required to characterize the components in the cactus extract. Separation of the cactus extract components can be achieved via preparative HPLC, followed by characterization of the separated compounds by nuclear magnetic resonance (NMR) or tandem mass spectrometry. Alternatively, separation and characterization of the cactus extract components can be performed by liquid chromatography tandem mass spectrometry (LCMS/MS). Preliminary work done by HPLC suggest that the cactus extract contains several components, with the main compound eluting at 2.204 minutes (Fig. 10).

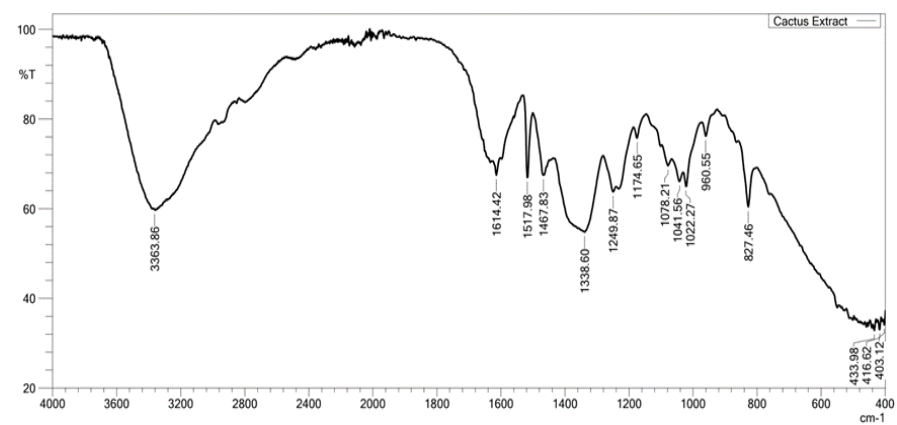

Fig. 9 The IR spectrum of cactus extract. The spectrum was recorded using a Perkin Elmer Lambda 2 FTIR.

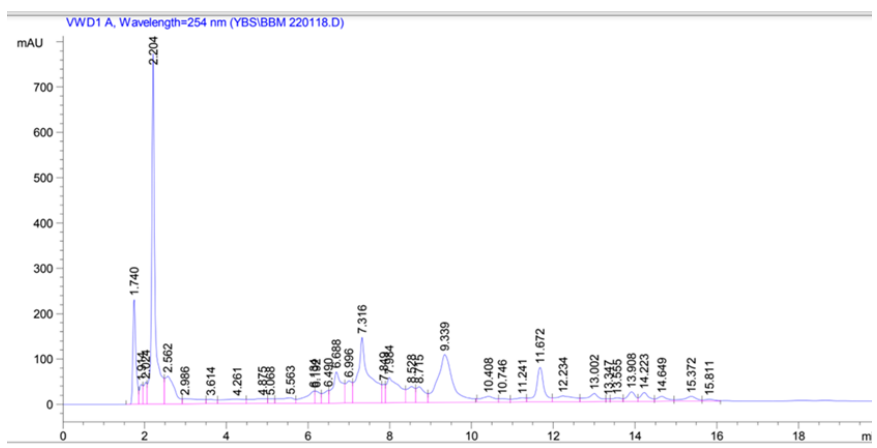

Fig. $10 \mathrm{HPLC}$ chromatogram of cactus extract $(3.78 \mathrm{mg} / \mathrm{mL})$ recorded at the wavelength of $254 \mathrm{~nm}$.

\section{The effect of cactus extract on the SPF of octocrylene and oxybenzone}

The cactus extract was mixed with each of the sunscreen agent in 95\% ethanol. The final concentration of cactus extract in each of the sunscreen solutions was $3.78 \mathrm{mg} / \mathrm{mL}$. The concentration of oxybenzone was $20 \mu \mathrm{g} / \mathrm{mL}$ and the concentration of octocrylene was $5 \mu \mathrm{g} / \mathrm{mL}$. The cactus extract was shown to significantly increase the SPF of oxybenzone and octocrylene solutions (Figs. 11 and 12). However, the mechanism of the SPF-enhancing properties of the cactus extract on the SPF of octocrylene and oxybenzone remains to be investigated.

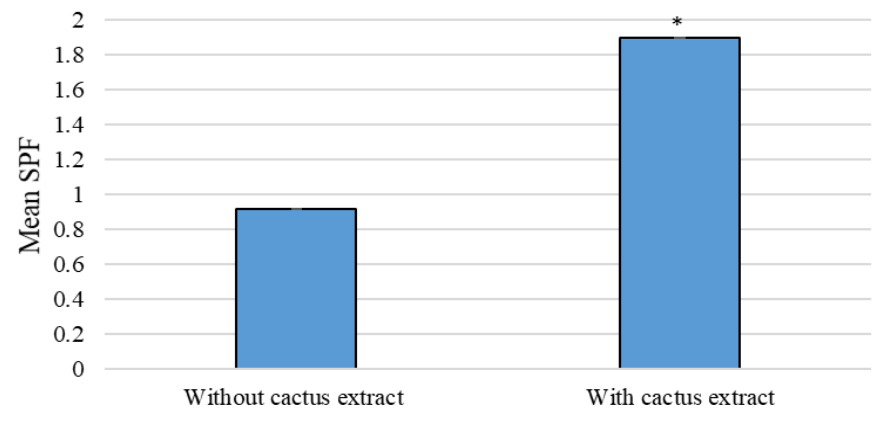

Mean SPF of oxybenzone solution

Fig. 11 The mean SPF $(n=3)$ of oxybenzone solution $(20 \mu \mathrm{g} / \mathrm{mL})$, with and without the cactus extract $(3.78 \mathrm{mg} / \mathrm{mL})$. Significant difference $(p<0.05)$ in SPF of oxybenzone solution with cactus extract, compared to oxybenzone solution only is indicated by the asterisk sign.

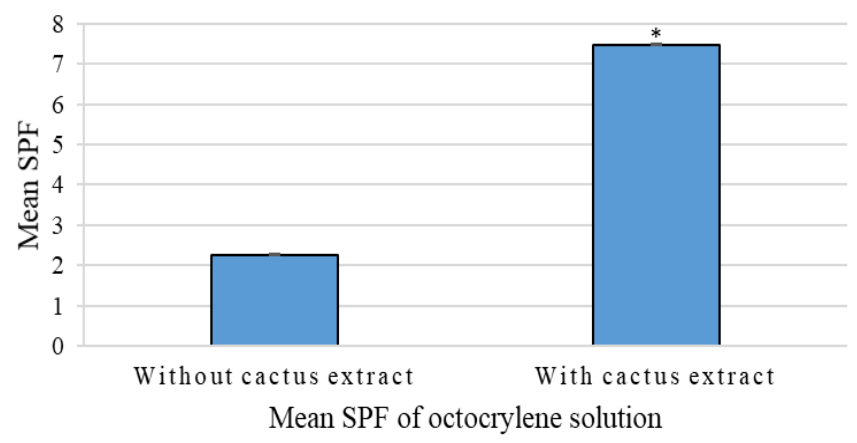

Fig. 12 Mean SPF $(n=3)$ of octocrylene solution $(5 \mu \mathrm{g} / \mathrm{mL})$, with and without cactus extract $(3.78 \mathrm{mg} / \mathrm{mL})$. Significance difference $(p<0.05)$ in SPF of octocrylene solution with cactus extract, compared to octocrylene solution only is indicated by the asterisk sign.

\section{CONCLUSION}

Antioxidants are frequently added into sunscreen formulations to enhance the photo protection benefit of the product due to their radical quenching abilities, and to maintain stability of the product. The results from this work suggests that antioxidants may also increase the photo protection benefit of sunscreen formulations by increasing the SPF. $\alpha$ Tocopherol and $\beta$-carotene were found to increase the SPF of octocrylene and oxybenzone solutions the most. To the best of our knowledge, the present work is the first to demonstrate the SPF enhancing properties of caffeine, nicotinamide, $\alpha$-tocopherol, and $\beta$ carotene in octocrylene and oxybenzone solutions. Although the exact mechanism is not clear, this work suggests that additional photoprotection may be achieved by appropriate mixtures of sunscreen agents and antioxidants. In addition to the antioxidants, cactus extract was also shown to increase the SPF of the sunscreen agents.

\section{ACKNOWLEDGEMENT}

This work was financially supported by the International Medical University (IMU), Kuala Lumpur. The authors would also like to express their deepest thanks to Dr. Ho Ket Li from the Department of Life Sciences, IMU for his help on the statistical analysis. 


\section{REFERENCES}

Ammar, I., Ennouri, M., \& Attia, H. (2015). Phenolic content and antioxidant activity of cactus (Opuntia ficus-indica L.) flowers are modified according to the extraction method. Industrial Crops \& Products, 64, 97-104.

D’Orazio, J., Jarrett, S., Amaro-Ortiz, A., \& Scott, T. (2013). UV radiation and the skin. International Journal of Molecular Sciences, 14(6), 1222212248.

Damian, D. L. (2010). Photoprotective effects of nicotinamide. Photochemical \& Photobiological Sciences, 9(4), 578-585.

Darvin, M. E., Fluhr, J. W., Meinke, M. C., Zastrow, L., Sterry, W., \& Lademann, J. (2011). Topical beta-carotene protects against infra-redlight-induced free radicals. Experimental Dermatology, 20(2), 125-129.

Darvin, M. E., Fluhr, J. W., Schanzer, S., Rishter, H., Patzelt, A., Meinke, M. C., Zastrow, L., Golz, K., Doucet, O., Sterry, W., \& Lademann, J. (2011). Dermal carotenoid level and kinetics after topical and systemic administration of antioxidants: Enrichment strategies in a controlled in vivo study. Journal of Dermatological Science, 64(1), 53-58.

Dreher, F., Gabard, B., Schwindt, D. A., \& Maibach, H. I. (1998). Topical melatonin in combination with vitamins $\mathrm{E}$ and $\mathrm{C}$ protects skin from ultraviolet-induced erythema: A human study in vivo. British Journal of Dermatology, 139(2), 332-339.

Dutra, E. A., Oliveira, D. A. G. da C., Kedor-Hackmann, E. R. M., \& Santoro, M. I. R. M. (2004). Determination of sun protection factor (SPF) of sunscreens by ultraviolet spectrophotometry. Revista Brasileira de Ciências Farmacêuticas, 40(3), 381-385.

Ebrahimzadeh, M. A., Enayatifard, R., Khalili, M., Ghaffarloo, M., Saeedi, M., \& Charati, J. Y. (2014). Correlation between sun protection factor and antioxidant activity, phenol and flavonoid contents of some medicinal plants. Iranian Journal of Pharmaceutical Research, 13(3), 1041-1047.

Fernández-López, J. A., Almela, L., Obón, J. M., \& Castellar, R. (2010). Determination of antioxidant constituents in cactus pear fruits. Plant Foods for Human Nutrition, 65(3), 253-259.

Freitas, J. V., \& Gaspar, L. R. (2016). In vitro photosafety and efficacy screening of apigenin, chrysin and beta-carotene for UVA and VIS protection. European Journal of Pharmaceutical Sciences, 89, 146-153.

Freitas, J. V., Lopes, N. P., \& Gaspar, L. R. (2015). Photostability evaluation of five UV-filters, trans-resveratrol and beta-carotene in sunscreens. European Journal of Pharmaceutical Sciences, 78, 79-89.

Freitas, J. V., Praça, F. S. G., Bentley, M. V. L. B., \& Gaspar, L. R. (2015). Trans-resveratrol and beta-carotene from sunscreens penetrate viable skin layers and reduce cutaneous penetration of UV-filters. International Journal of Pharmaceutics, 484(1-2), 131-137.

Herman, A., \& Herman, A. P. (2012). Caffeine's mechanisms of action and its cosmetic use. Skin Pharmacology and Physiology, 26, 8-14.

Keen, M., \& Hassan, I. (2016). Vitamin E in dermatology. Indian Dermatology Online Journal, 7(4), 311-314.
Khamsiah, N., Lai, N., Nurfarhanim, M., Ar, N., Mohd Syazwan, C., \& Goon, J. (2012). Photoprotective measures of selected sunscreens and their antioxidant adjuvantion effects in the Malaysian climate. Medicine and Health, 7(2), 84-96.

Latha, M. S., Martis, J., Shobha, V., Shinde, R. S., Bangera, S., Krishnankutty, B., Bellary, S., Varughese, S., Rao, P., \& Kumar, B. R. N. (2013). Sunscreening agents: A review. Journal of Clinical and Aesthetic Dermatology, 6(1), 16-26.

Mansur, J. de S., Breder, M. N. R., Mansur, M, C. D. A., \& Azulay, R. D. (1986). Determinação do fator de proteção solar por espectrofotometria. Anais Brasileiros de Dermatologia, 61(3), 121-124.

Matsui, M. S., Hsia, A., Miller, J. D., Hanneman, K., Scull, H., Cooper, K. D., \& Baron, E. (2009). Non-sunscreen photoprotection: Antioxidants add value to a sunscreen. Journal of Investigative Dermatology Symposium Proceedings, 14(1), 56-59.

Monico, G., Leo, M., Ma, B., Johal, R. S., Ma, T., \& Sivamani, R. K. (2015). The use of botanical products and vitamins in sunscreens. Dermatology Online Journal, 21(11), 1-52.

Pinnell, S. R. (2003). Cutaneous photodamage, oxidative stress, and topical antioxidant protection. Journal of the American Academy of Dermatology, $48(1), 1-19$.

Pirotta, G. (2015). An overview of sunscreen regulations in the world. Household and Personal Care Today, 10(4), 17-20.

Saewan, N., \& Jimtaisong, A. (2013). Photoprotection of natural flavonoids. Journal of Applied Pharmaceutical Science, 3(9), 129-141.

Sayre, R. M., Agin, P. P., Le Vee, G. J., \& Marlowe, E. (1979). A comparison of in vivo and in vitro testing of sunscreening formulas. Phytochemistry and Photobiology, 29, 559-566.

Sheraz, M. A., Khan, M. F., Ahmed, S., Kazi, S. H., \& Ahmad, I. (2015). Stability and stabilization of ascorbic acid. Household and Personal Care Today, 10(3), 22-25.

Sheraz, M. A., Ahmad, S., Ahmed, I., Shaikh, R., Vaid, F. H. M., \& Iqbal, K. (2011). Formulation and stability of ascorbic acid in topical preparations. Systematic Reviews in Pharmacy, 2(2), 86-90.

Stahl, W., \& Sies, H. (2012). $\beta$-Carotene and other carotenoids in protection from sunlight. American Journal of Clinical Nutrition, 96(5), 1179-1184.

Wang, S. Q., Osterwalder, U., \& Jung, K. (2011). Ex vivo evaluation of radical sun protection factor in popular sunscreens with antioxidants. Journal of the American Academy of Dermatology, 65(3), 525-530.

Wohlrab, J., \& Kreft, D. (2014). Niacinamide - Mechanisms of action and its topical use in dermatology. Skin Pharmacology and Physiology, 27(6), 311-315.

Wu, Y., Matsui, M. S., Chen, J. Z. S., Jin, X., Shu, C. M., Jin, G. Y., Dong, G. H., Wang, Y. K., Gao, X. H., Chen, H. D \& Li, Y. H. (2011). Antioxidants add protection to a broad-spectrum sunscreen. Clinical and Experimental Dermatology, 36(2), 178-187.

Yuan, J. P., \& Chuan, F. (1998). Degradation of ascorbic acid in aqueous solution. Journal of Agricultural and Food Chemistry, 46, 5078-5082. 